\title{
Curcuma zerumbet (Zingiberaceae) Rhizome Extracts Thermal Characterization Through TG, DTA and DSC Analysis
}

\author{
Castro $\mathrm{M}^{1 *}$, Pinheiro $\mathrm{C}^{2}$, Marinho $\mathrm{H}^{2}$ and Porcu $\mathrm{OM}^{3}$ \\ ${ }^{1}$ Post-Graduation on Biotechnology, Federal University of Amazonas, Brazil \\ ${ }^{2}$ National Research Institute of the Amazon, Thematic Laboratory of Natural Products, Brazil \\ ${ }^{3}$ Federal Technological University of Paraná Câmpus Medianeira, Brazil
}

*Corresponding author: Castro M, Federal University of Amazonas, Post-Graduation on Biotechnology, Amazonas-Brazil, Av. Gal. Rodrigo Otávio Jordão Ramos, 3000, Coroado, University Campus, CEP: 69077000, Brazil

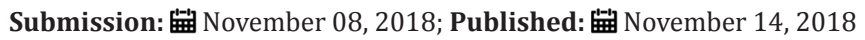

\begin{abstract}
The present work aims to achieve the thermal characterization of the water and hydroalcoholic extracts from the rhizome of Curcuma zerumbet through TG, DTA and DSC thermoanalytic as well phytochemical analysis from three different geographical sites. Dynamical assays at the 30 to 300 ${ }^{\circ} \mathrm{C}$ range were conducted so as to ascertain whether the extracts could be utilized in every food production process regardless of their temperature and studied the essential oil from them through GC-MS. The expressed results indicated these extracts cannot be utilized in the food manufacturing processes above $100{ }^{\circ} \mathrm{C}$ due to the degradation of bioactive components such as curcuminoids and/or curzerenone, compounds with pharmacological properties.
\end{abstract}

Keywords: Curcuma zerumbet; Thermogravimetry; Natural extracts

\section{Introduction}

Genus Curcuma belongs to Family Zingiberaceae and possesses over 70 species. This genus is endemic to the Indo-Malayan regions, where the species are grown and therapeutically utilized by the population in India, China and Indonesia [1]. In Brazil, only the Curcuma longa species is being utilized for therapeutic ends whereas the other ones are utilized for ornamental purposes, mainly those occurring in the State of Amazonas. One of the main components extracted from this genus is the curcumin, which is also responsible for its bioactive activities. The literature describes its positive effects when used in several forms, such as extracts, solutions and, oral and intraperitoneal administration [2]. One of the species of exotic occurrence in the State of Amazonas is Curcuma zerumbet, which is utilized by many residents as an ornamental plant, and yet, some people use it for therapeutic purposes (roots and rhizomes) [3], which may be employed in the form of infusion, decoction, tincture, powder or chewable pieces. Curcumin contents present in the rhizome extracts may undergo some changes during boiling or heating, therefore it should undergo analyses. However, providing useful information about the characteristic changes during its heating [4] is important, since it becomes useful for maximizing the quality of the material and minimizing the losses during the thermal treatment [5] (Brazzoli et al, 2007). Thus, information pertaining to these extracts during thermal processing, and its application on the actual process undertaking, would be beneficial for the development of new Curcuma zerumbet-based food products. Once there are no published reports addressing its extracts during heating processing as of yet, the present study aims to characterize the Curcuma zerumbet rhizome hydroalcoholic and water extracts thermal behavior.

\section{Material and Methods}

\section{Samples}

Samples of species Curcuma zerumbet were collected in the Community Tarumã-mirim, Ramal do Pau Rosa, BR 174, Km 21, Latitude $2^{\circ} 43^{\prime} 17^{\prime \prime}$, Longitude $60^{\circ} 08^{\prime} 19^{\prime \prime} \mathrm{W}$, located in the State of Amazonas/Brazil. The sample was deposited in the herbaria of the National Institute for Research in Amazonia (INPA), under $\mathrm{n}^{0} 003$. Rhizomes were washed in running water, dried in an oven with circulating air at $45{ }^{\circ} \mathrm{C}$ for $24 \mathrm{~h}$. After, they were ground in a semiindustrial liquidizer and the following extracts were prepared.

\section{Preparation of the extracts}

Extraction of essential oil: We attained the essential oil through the hydro distillation process by utilizing the Clevenger device coupled to a balloon, into which we added $200 \mathrm{~g}$ of the rhizome per $1.5 \mathrm{~mL}$ of distilled water. The essential oil was stored in dark at $4{ }^{\circ} \mathrm{C}$ until used for experimentation.

Water Extract: We weighed $50 \mathrm{~g}$ of the powder of the rhizome from C. zerumbet and diluted in $1000 \mathrm{~mL}$ of distilled water. 
Heated it in a closed beaker for about 15 minutes, cooled to room temperature and filtered [6]. The material was dehydrated through the lyophilization process utilizing LS 3000 (TERRONI®) for 48h.

Hydroalcoholic Extract: $200 \mathrm{~g}$ rhizome powder from $C$. zerumbet was extracted through $2000 \mathrm{~mL}$ of solvent (ethanol and distilled water). Extraction was carried out through classic maceration for $72 \mathrm{~h}$ at room temperature. Subsequently, the extract was, filtered through a filter paper (Whatman $\mathrm{N}^{\circ} 1$ ) and evaporated under reduced pressure by rotary evaporator (Tecnal rotavapor TE211). After evaporation of the solvent, the obtained crude extract was stored in the fridge at $+4^{\circ} \mathrm{C}$ for further experiment.

Gas chromatography-mass spectrometry-GC-MS: To prepare the sample to be injected into the mass spectrometer-coupled gas chromatographer, we utilized one $\mu \mathrm{L}$ of oil diluted into one $\mathrm{mL}$ of dichloromethane in QP2010MS Shimadzu chromatographer. The mass spectrometer performed the analyses in scan mode $(40-600 \mathrm{~m} / \mathrm{z})$ and the capillary column $(30 \mathrm{~m}$ long with 0.25 d.i. and $0.25 \mu \mathrm{m}$ of film), with a stationary phase made up of $5 \%$ of phenyl-methyl poly-siloxane. The planning that enabled the chromatographic peaks resolution showed to be the following analysis condition: Initial column temperature: $60^{\circ} \mathrm{C}$, Final column temperature: $240{ }^{\circ} \mathrm{C}$, Injector temperature: $250^{\circ} \mathrm{C}$.

Thermal analysis of extracts: Extracts were submitted to the following thermal analysis techniques: Thermogravimetry

Table 1: Identification of the active components of the essential oil from Curcuma zerumbet detected by CG-MS.

\begin{tabular}{|c|c|c|}
\hline Components & Retention Time (min.) & $\%$ area \\
\hline camphene & 6.88 & 0.46 \\
\hline sabinemo & 7.199 & 0.53 \\
\hline$(-)-\alpha$-terpineno & 10.35 & 0.69 \\
\hline$(+)$-camphor & 15.98 & 2.23 \\
\hline isoborneol & 16.465 & 1.08 \\
\hline cumin aldehyde & 17.872 & 0.3 \\
\hline Y-elemene & 25.799 & 5.96 \\
\hline abulnesene & 27.218 & 0.63 \\
\hline$\beta$-farnesene & 28.517 & 1.97 \\
\hline caryophillene oxide & 29.943 & 0.81 \\
\hline cycloisolongifolene, 8,9-dehydro-9-formyl & 30.379 & 0.67 \\
\hline naphtalene & 30.567 & 0.58 \\
\hline elemol & 30.661 & 2.4 \\
\hline arlloaromadendrene oxide-(2) & 33.288 & 0.64 \\
\hline cadinol & 34.667 & 0.4 \\
\hline selin-11-en-4-a-ol & 34.781 & 0.58 \\
\hline curzeronone & 35.543 & 49.45 \\
\hline epi-curzerenone & 35.799 & 3.04 \\
\hline farnesol & 36.294 & 1.19 \\
\hline curcumenol & 37.643 & 0.63 \\
\hline- & 38.996 & 2.91 \\
\hline acetato de bisabolol & 40.027 & 5.2 \\
\hline
\end{tabular}




\begin{tabular}{|c|c|c|}
\hline bisabolone & 40.175 & 0.79 \\
\hline $1,6,10,14$-hexadecatetraen-3-ol,3,7,11,15-tetramethyl & 40.462 & 0.97 \\
\hline acarone & 40.606 & 1.9 \\
\hline cyclopentadecanolide & 40.983 & 2.51 \\
\hline hillyl acetato & 41.198 & 2.34 \\
\hline hexacandenol & 42.395 & 2.05 \\
\hline cis-farnesol & 42.745 & 5.04 \\
\hline- & 44.498 & 0.9 \\
\hline- & 49.155 & 1.15 \\
\hline
\end{tabular}

\section{Extracts thermal analysis}

The thermogram from (Figure 1) by thermogravimetric (TG) at $10{ }^{\circ} \mathrm{C} \mathrm{min}^{-1}$ for the water extract of Curcuma zerumbet showed the initial stage of decomposition, at approximately $33^{\circ} \mathrm{C}$ to 130 ${ }^{\circ} \mathrm{C}$, which we may attribute to the sample's dehydration profile. Further loss was occurred at $225^{\circ} \mathrm{C}$ and proceed further at $300{ }^{\circ} \mathrm{C}$. The compound showed a relatively high mass loss, about $55 \%$, in the studied temperature gap. Whereas, the hydroalcoholic extract showed first dehydration stage at approximately $50{ }^{\circ} \mathrm{C}$ then took place from around $225^{\circ} \mathrm{C}$ onward. Thermal events by DSC (Figure 2 ), showed an endothermic peck at around $60^{\circ} \mathrm{C}$, which may be attributed to the water extract dehydration and consequent mass loss. From $200{ }^{\circ} \mathrm{C}$ onward, we observed the base line to present a deviation. Policegoudra and Aradhya [12] verified curcuma rhizome DSC slopes to vary: Curcuma longa $27{ }^{\circ} \mathrm{C}$; Curcuma zedoaria $33{ }^{\circ} \mathrm{C}$ and Curcuma manga $79^{\circ} \mathrm{C}$, there being no standard parameter that would enable them to be compared. According to their studies, this analysis was influenced by the molecular weight and structure of the amylopectins present in the rhizomes of the species. DSC slope characterized an endothermic transition at around $60{ }^{\circ} \mathrm{C}$ for the hydroalcoholic extract, which one may attribute to the loss of water absorbed by the sample. At around $200{ }^{\circ} \mathrm{C}$ there occurred another endothermic transition attributed to organic matter decomposition.

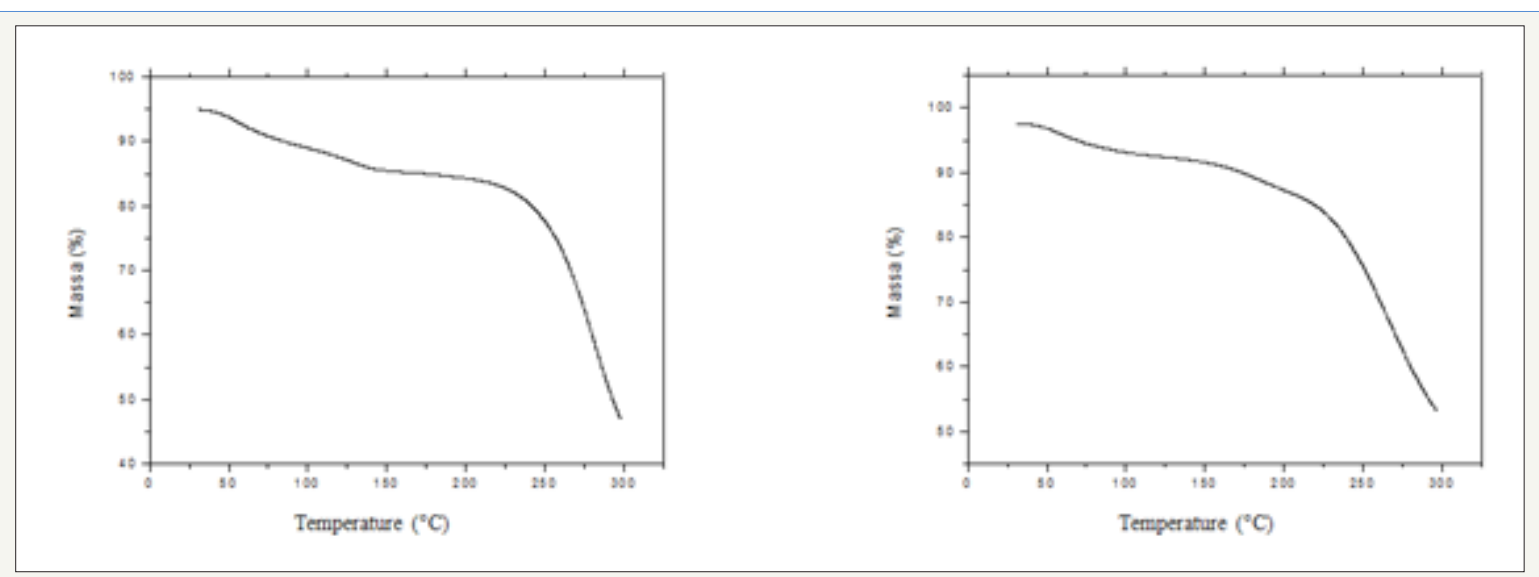

Figure 1: TG Thermogravimetry profile attained for the Curcuma zerumbet water and hydroalcoholic extract, respectively, under dynamic, synthetic air atmosphere with $50 \mathrm{~mL} \cdot \mathrm{min}^{-1}$ outflow, $10{ }^{\circ} \mathrm{C} \cdot \mathrm{min}^{-1}$ heating rate and support of a- $\mathrm{Al}_{2} \mathrm{O}_{3}$ with lid.

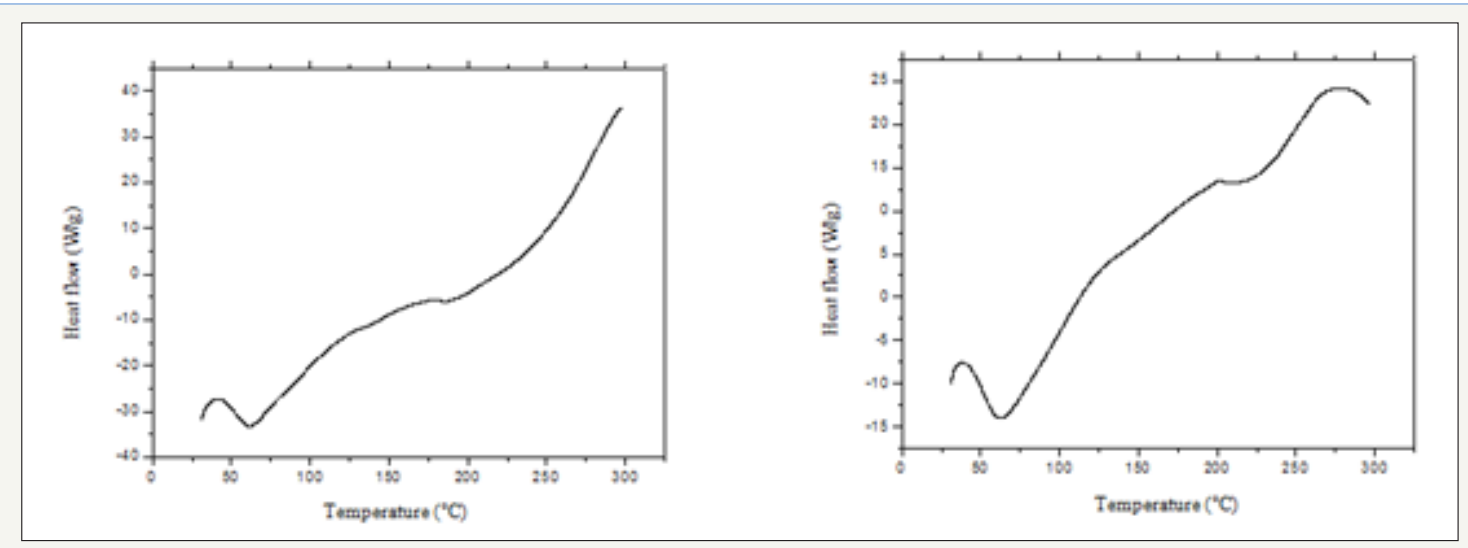

Figure 2: Graphic expression of the DSC sloped attained for Curcuma zerumbet water and hydroalcoholic extracts, respectively, under dynamic, synthetic air atmosphere with $50 \mathrm{~mL} \cdot \mathrm{min}^{-1}$ outflow, $10{ }^{\circ} \mathrm{C} \mathrm{min}^{-1}$ heating rate, a- $\mathrm{Al}_{2} \mathrm{O}_{3}$ support with lid. 


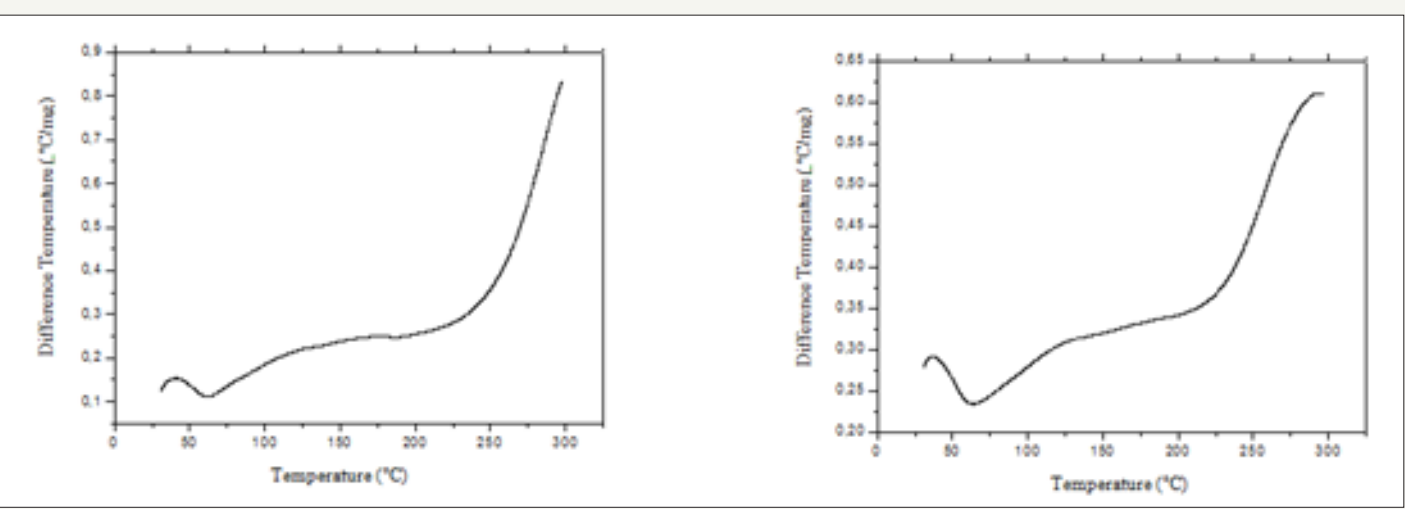

Figure 3: Curcuma zerumbet respective water and hydroalcoholic extracts DTA soles obtained under dynamic, synthetic air atmosphere with $50 \mathrm{~mL} \cdot \mathrm{min}^{-1}$ outflow, $10{ }^{\circ} \mathrm{C} \cdot \mathrm{min}^{-1}$ heating rate, a- $\mathrm{Al}_{2} \mathrm{O}_{3}$ support with lid.
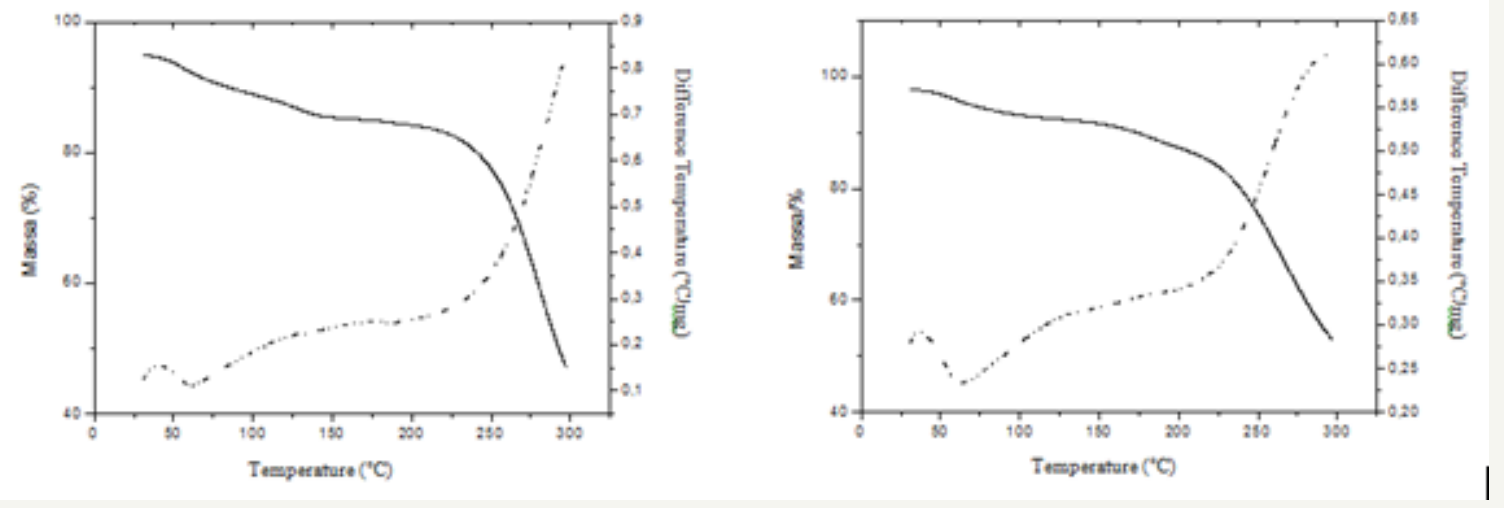

Figure 4: TG/DTA slopes of the Curcuma zerumbet water and hydroalcoholic extracts, respectively obtained under dynamic synthetic air atmosphere with $50 \mathrm{~mL} \cdot \mathrm{min}^{-1}$ outflow, $10{ }^{\circ} \mathrm{C} \cdot \mathrm{min}^{-1}$ heating rate, support of a- $\mathrm{Al}_{2} \mathrm{O}_{3}$ with lid.

DTA slope (Figure 3) showed similar behavior, with an endothermic peak as the one observed on the same decomposition stage referred to on the aqueous extract DSC slope at around 60 ${ }^{\circ} \mathrm{C}$ establishing a dehydration step. Hydroalcoholic extract DTA slope presented the same DSC slope endothermic peak at around $60{ }^{\circ} \mathrm{C}$, followed by another higher reaching endothermic peak, followed by more intensified decomposition step. In the TG/DTA slope (Figure 4) the water extract decomposition steps are not well defined, nevertheless, two different, yet close to each other decomposition steps, were characterized. The first step occurred at approximately $70{ }^{\circ} \mathrm{C}$ with an initial small mass loss of around $5 \%$, which is probably due to the presence of water absorbed from the environment and, the further loss through volatility of the water contained in the sample. The second step began close to $165^{\circ} \mathrm{C}$, losing little mass. However, at around $215^{\circ} \mathrm{C}$ the mass loss became sharp, which may demonstrate the organic matter decomposition. The sample loses as a whole approximately $67 \%$ of its mass at the analyzed temperature $\left(300^{\circ} \mathrm{C}\right)$. In the TG/DTA slope for the hydroalcoholic extract, the decomposition steps are not well defined. Yet, at around $210{ }^{\circ} \mathrm{C}$, there occurred a loss of $62 \%$ of mass which, may be attributed to the organic matter decomposition [13].

\section{Conclusion}

Based on these findings, one may assert that, after being analyzed through thermo analytical techniques, the aqueous and hydroalcoholic extracts from the rhizome of Curcuma zerumbet belong to three different geographical sites, demonstrated that, from $150{ }^{\circ} \mathrm{C}$ onwards, there was a sharp loss of mass in the extracts indicating probable degradation of carbohydrates and denaturation of biomolecules. On the other hand, these data indicated the sample of Curcuma zerumbet instability at high temperature.

\section{References}

1. Murnigsih T, Subeki, Matsuura H, Takahashi K, Yamasaki M (2005) Evaluation of Indohesion traditional medicinal plants agains Plasmodium falciparum and Babesia gibsoni J Vet Med Sci 67(8): 829-931.

2. Costa NMB, Rosa COB (2010) Functional Foods: Bioactive components and effects. In: Janeiro R (Ed.), Rubio, p. 536.

3. Castro MS, Pinheiro CCS, Marinho HA, Amadis BF (2018) Evaluation of Curcuma zerumbet (Zingiberaceae) rhizome extracts sub-acute toxicity on Wistar rats. African Journal of Biotechnology 17(3): 922-927.

4. Takeo 0 (2000) Thermal analysis-review and prospect. Thermochinica Acta 355(1-2): 35-42.

5. Balsa Canto E, Rodriguez Fernandez M, Banga JR (2007) Optimal design of dynamic experiments for improved estimation of kinetic parameters of thermal degradation. Journal of Food Engineering 82(2): 178-188.

6. Schulz V, Hansel R, Tyler VE (2002) Rational phytotherapy: A guide to phytotherapy for the health sciences ( $1^{\text {st }}$ edn). Manole, Barueri, Brazil.

7. Zhou L, Zhang K, Li J, Cui X, Wang A, et al. (2013) Inhibition of vascular endothelial growth factor-mediated angiogenesis involved in reproductive toxicity induced by sesquiterpenoids of Curcuma zedoaria in rats. Reprod Toxicol 37: 62-69. 
8. Yang FQ Wang HK, Chen H, Chen JD, Xia ZN (2011) Fractionation of voltile constituents from Curcuma rhizome by preparative gas chromatography. Journal of Automated Methods and Management in Chemistry 6: 145151.

9. Joshi SC, Mathela CS (2012) Antioxidant and antibacterial activitier of the leaf essencial oil and its constituents furanodienone and curzerenone from Lindera pulcherrina (Nees) Benth. ex hook. f. Pharmacognosy Res 4(2): 80-84.

10. Yang FQ Li SP, Wang YT, Chen Y, Lao SC, et al. (2005) Identification and quantitation of eleven sesquiterpenes in three species of Curcuma rhizomes by pressurized liquid extraction and gas chromatographymass spectrometry. J Pharm Biomed Anal 39(3-4): 552-558.
11. Yang FQ, Li SP, Zhao J, Lao SC, Wang YT (2007) Optimization of CG-MS conditions based on resolution and stability of analytes simultaneous determination of nine sesquiterpenoids in three species of Curcuma rhizomes. J Pharm Biomed Anal 43(1): 73-82.

12. Policegoudra RS, Aradhya SM (2008) Structure and biochemical properties of starch from an unconventional source-Mango ginger (Curcuma amada Roxb) rhizome. Food Hydrocolloids 22(4): 513-519.

13. List PH, Schimidt PC (1989) Phytopharmaceutical technology. ( $1^{\text {st }}$ edn $)$. CRC Press, Londor, USA.
Creative Commons Attribution 4.0 International License

For possible submissions Click Here

\section{Submit Article}

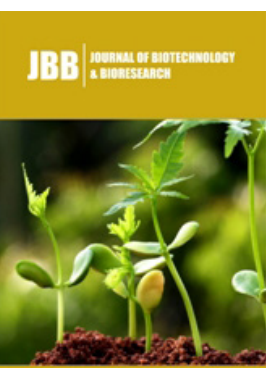

Journal of Biotechnology \& Bioresearch

\section{Benefits of Publishing with us}

- High-level peer review and editorial services

- Freely accessible online immediately upon publication

- Authors retain the copyright to their work

- Licensing it under a Creative Commons license

- Visibility through different online platforms 